\title{
Beta-Haemolytic Group A, C and G Streptococcal Infections in Southern Hungary: A 10-Year Population-Based Retrospective Survey (2008-2017) and a Review of the Literature
}

This article was published in the following Dove Press journal:

Infection and Drug Resistance

\author{
Márió Gajdács' \\ Marianna Ábrók ${ }^{2}$ \\ Andrea Lázár ${ }^{2}$ \\ Katalin Burián ${ }^{2,3}$ \\ 'Department of Pharmacodynamics and \\ Biopharmacy, Faculty of Pharmacy, \\ University of Szeged, Szeged 6720, \\ Hungary; ${ }^{2}$ Institute of Clinical \\ Microbiology, Faculty of Medicine, \\ University of Szeged, Szeged, Hungary; \\ ${ }^{3}$ Department of Medical Microbiology, \\ Faculty of Medicine, University of Szeged, \\ Szeged 6720, Hungary
}

Introduction: Pyogenic $\beta$-hemolytic streptococci (including Group A, C and G Streptococcus) are some of the most important Gram-positive bacterial pathogens in human medicine. Although effective therapy is available, invasive streptococcal infections are associated with a significant disease burden.

Methods: In this retrospective study, the epidemiological characteristics of invasive Group A (iGAS) and Group C and G (iGCGS) streptococci, along with tonsillo-pharyngitis-causing pGAS and pGCGS infections, were assessed in Southern Hungary. A total of 1554 cases of streptococcal tonsillo-pharyngitis infections (26.5-44.1/100,000 persons, pGAS: $95.5 \%$; $\mathrm{n}=1484)$ and 1104 cases of invasive streptococcal infections were detected (12.5-31.4/ 100,000 persons, iGAS: $77.9 \%$; $\mathrm{n}=861$ ).

Results: The average age of the affected patients in the various groups were the following: pGAS: $13.2 \pm 13.1$ years, pGCGS: $21.0 \pm 15.0$ years $(\mathrm{p}=0.039)$, iGAS: $49.1 \pm 12.8$ years, iGCGS: $58.7 \pm 18.5$ years $(\mathrm{p}>0.05)$. iGAS isolates originated from abscesses $(47.1 \%)$, blood culture samples (24.1\%), surgical samples (16.7\%), biopsies (4.6\%), pleural fluid (3.5\%), pus $(2.0 \%)$, synovial fluid (1.3\%) and cerebrospinal fluid samples (0.7\%). In contrast, iGCGS isolates mainly originated from blood culture samples $(53.8 \%)$, abscesses $(22.9 \%)$, surgical samples $(12.3 \%)$, synovial fluid (5.1\%), pleural fluid (3.7\%), pus (1.8\%) and cerebrospinal fluid samples $(0.4 \%)$. All respective isolates were susceptible to benzyl-penicillin; overall resistance levels for erythromycin (10.5\% for GAS, $21.4 \%$ for GCGS) and clindamycin $(9.2 \%$ for GAS, $17.2 \%$ for GCGS) were significantly higher in GCGS isolates, while resistance levels for norfloxacin were higher in GAS isolates (13.5\% for GAS, 6.9\% for GCGS).

Conclusion: The rates of resistance to macrolides and clindamycin are a cause for concern (especially among GCGS isolates); however, resistance levels are still relatively low, compared to Southern European countries.

Keywords: epidemiology, antibiotics, group A Streptococcus, group C Streptococcus, group G Streptococcus, Hungary, Streptococcus pyogenes, Streptococcus dysgalactiae subspecies equisimilis

\section{Introduction}

Pyogenic $\beta$-hemolytic streptococci (consisting of Streptococcus pyogenes [Group A Streptococcus; GAS], S. agalactiae [Group B Streptococcus], S. dysgalactiae subsp. equisimilis (SDSE; relevant in human disease) and S. dysgalactiae subsp.
Department of Pharmacodynamics and Biopharmacy, Faculty of Pharmacy, University of Szeged, Eötvös Utca 6, Szeged 6720, Hungary

Tel +36-63-34l-330

Email gajdacs.mario@pharm.u-szeged.hu
Infection and Drug Resistance 2020:13 4739-4749

4739

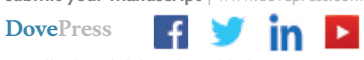

http://doi.org/10.2147/10R.S279157 
dysgalactiae (SDSD; relevant in animal disease) [Group C and Group G Streptococcus; GCS and GGS]) are some of the most important Gram-positive bacterial pathogens in human medicine, especially in the paediatric population. ${ }^{1-5}$ Streptococci were classified according to the Lancefield-grouping, a system based on the composition of the cell wall antigens; ${ }^{6}$ although some believe that this classification has outlived its usefulness in the era of whole genome sequencing (WGS), Lancefield-grouping is still frequently used in routine clinical practice. ${ }^{7}$

GAS and GCS/GGS species are taxonomically very close, with a $72 \%$ sequence similarity; in addition, these bacteria share many virulence factors (eg, the M protein, encoded by the $\mathrm{emm}$ genes, surface proteins, fibronectin (Fn)-binding proteins, streptolysin $\mathrm{S}$ and streptolysin O). ${ }^{8-11}$ Due to their pronounced tissue tropism, GAS and GCS/GGS isolates frequently occur as colonizers of the skin, oropharynx, alimentary tract and genito-urinary region. ${ }^{12}$ In fact, a recent metaanalysis has reported that the prevalence of GAS carriage in children was $12 \%$, while other report concluded that GCS/ GGS carriage in all age groups was around $4 \%$; however, carriage rates may vary greatly based on seasonality and different geographical regions. ${ }^{13,14}$ Nevertheless, they are also highly pathogenic, capable of causing a wide spectrum of illnesses, being an important factor of morbidity and mortality. ${ }^{15}$ Mild manifestations may include tonsillopharyngitis ("strep throat"), wound infections and impetigo, ${ }^{16}$ while severe infections, such as scarlet fever, ${ }^{17}$ endophthalmitis, ${ }^{18}$ mastoiditis, ${ }^{19}$ septic arthritis, ${ }^{20}$ osteomyelitis, ${ }^{21}$ necrotizing fasciitis, ${ }^{22}$ puerperal infections, ${ }^{23}$ bacteremia and sepsis, ${ }^{24}$ meningitis, ${ }^{25}$ endocarditis, ${ }^{26}$ and streptococcal toxic shock syndrome (STSS) ${ }^{27}$ may also occur. In addition, clinicians must take into consideration the emergence of post-streptococcal manifestations, such as rheumatic fever, rheumatic heart disease, glomerulonephritis and other immune-mediated complications. ${ }^{28}$

Although effective therapy is available, invasive streptococcal infections are associated with a significant disease burden, estimated at $>500,000$ worldwide deaths annually. ${ }^{29-32}$ In the United States, GAS is responsible for 1-2.5 million cases of tonsillo-pharyngitis, 12,000-25,000 invasive infections and around 1250-2000 deaths, according to the CDC database. While the importance of GAS in human infections is well-known, the importance of GCS/GGS species has only been studied extensively in recent times. ${ }^{33}$ This may be attributed to novel technical developments in clinical microbiology, in addition to the growing number of people in immunocompromised state, at higher risk for GCS/GGS infections. ${ }^{34}$ Several reports have highlighted the role of GCS/GGS in severe, invasive infections: in fact, GCS/GGS are responsible for $80 \%$ of invasive infections caused by non-GAS and non-GBS $\beta$ hemolytic streptococci, and in some countries, their incidence approaches that of invasive GAS infections. ${ }^{35,36}$ Many authors have also suggested the phenomenon of epidemiological differentiation between patients affected by GAS and GCS/GGS infections, ie, the incidence of GCS/GGS infections is reported to be higher among adult patients, both in tonsillo-pharyngitis and in invasive infections, and the resistance levels associated with GCS/GGS infections have also been reported to be higher. $^{37,38}$

The long-term surveillance of streptococcal infections is important for clinical medicine and for public health purposes; however, the availability of reports from Hungary and Central/Eastern Europe is scarce. In the present study, we report the epidemiological characteristics of pharyngitis and invasive infections caused by GAS and GCS/GGS in Southern Hungary over a 10-year surveillance period (2008-2017).

\section{Materials and Methods Study Site and Population}

The present retrospective study was carried out using epidemiological data/demographics and microbiological data collected between the period of 2008.01.01 and 2017.12.31 at the Institute of Clinical Microbiology (University of Szeged). The Institute acts as the affiliated diagnostic laboratory for the Albert Szent-Györgyi Clinical Center (ASCC), the principal primary- and tertiary-care teaching hospital in Southern Hungary and also receives microbiological samples from community-based healthcare-professionals in the region. ${ }^{39}$ The Clinical Center is equipped has a bed capacity of 1820 beds (1465 acute and 355 chronic beds, respectively), according to the data of the Hungarian National Health Insurance Fund (NEAK). ${ }^{40}$ The population of the region has decreased from 417,456 to 399,012 during the respective 10 -year period, based on Eurostat data for the region. As high as $27.5 \%$ of the population lives in rural areas, while the majority of the population lives in cities/towns.

\section{Data Collection}

Electronic search in the records of the MedBakter laboratory information system (LIS) for samples positive for 
GAS, GCS and GGS was conducted by the authors (M.G., Á.M. and A.L.). Age and sex of the patients, date of sample submission, sample type and indication for sample submission (including preliminary diagnoses) were collected. $^{39}$ During data analysis, affected patients were differentiated to two age groups: 0-17 year-olds and 18 and over, based on Oppegaard et al. ${ }^{38}$ Retrospective chart review of the affected patients was not performed; therefore, the incidence of chronic sequelae such as acute rheumatic fever, rheumatic heart disease or poststreptococcal glomerulonephritis was not assessed. ${ }^{41}$

Due to the very low number of group $\mathrm{C}$ streptococci and the fact that $\beta$-haemolytic group $\mathrm{C}$ and $\mathrm{G}$ streptococci causing human infections most frequently belong to the species SDSE, these bacteria were treated as one group (GCGS) for statistical purposes, based on Oppegaard et al. ${ }^{38}$ GAS and GCGS bacteria were categorized into two groups, namely tonsillo-pharyngitis-causing GAS/GCGS (pGAS and pGCGS) and GAS/GCGS causing invasive infections (iGAS and iGCGS). Cases of iGAS and iGCGS were defined as the isolation of a Group A or Group C/G Streptococcus from a sterile site (eg, blood, cerebrospinal fluid, pleural fluid, peritoneal fluid, pericardial fluid, surgical aspirate, bone, joint fluid, or internal body site) or from a wound culture accompanied by necrotizing fasciitis (NF) or streptococcal toxic shock syndrome (STSS), based on the criteria established by Rudolph et al. ${ }^{41}$ Repeatedly positive cultures with the same organism identified within 30 days of initial isolation were considered to be from a single episode. $^{41}$ Isolates considered as contaminants during microbiological analysis were excluded from the study. As an external control for our data, the incidence of scarlet fever (erythrogenic toxin-producing GAS; which is a reportable illness in Hungary) was collected from the National Bacteriological Surveillance database of the National Institute of Public Health (NNK) for the period of 2008-2017. Rates were expressed as $\mathrm{X} / 100,000$ persons.

\section{Bacterial Identification}

Processing of clinical samples submitted to the Institute of Clinical Microbiology was carried out according to guidelines for routine clinical bacteriology. Isolates were cultured on Columbia agar plates containing 5\% sheep blood (bioMérieux, Marcy-l'Étoile, France) and stored in Todd Hewitt broth (bioMérieux, Marcy-l'Étoile, France) with glycerol in a $-80^{\circ} \mathrm{C}$ freezer. All isolates have initially been identified based on macroscopic appearance after 24 h ( $\beta$-hemolysis, colony size), Gram-staining results and bacitracin sensitivity, which was followed-up by hippurate test, pyrrolidonylarylamidase (PYR) test (Remel, Lenexa, KS, USA) and slide agglutination test kit for Lancefield antigen grouping (Slidex Strepto-Kit, bioMerieux, Marcyl'Étoile, France). ${ }^{38,41}$ After 2013, this was complemented by matrix-assisted laser desorption/ionization time-offlight mass spectrometry (MALDI-TOF MS; Bruker Daltonics, Bremen, Germany). The methodology of sample preparation and the technical details for MALDI-TOF MS measurements were described elsewhere. ${ }^{42,43}$ The MALDI Biotyper RTC 3.1 software (Bruker Daltonics, Germany) and the MALDI Biotyper Library 3.1 were used for spectrum analysis. Identification was considered reliable on species-level, if the $\log ($ score) values were $\geq 2.300$. If there was a discrepancy between the identification and the agglutination test results, the identification results were taken into consideration (ie, irrespective of the outcome of the agglutination test, if an isolate was identified as $S$. pyogenes, it was grouped as GAS, and if an isolate was identified as $S$. dysgalactiae subsp. equisimilis, it was grouped as GCGS).

\section{Antibiotic Susceptibility Testing}

Antimicrobial susceptibility testing (AST) was performed using the Kirby-Bauer disk diffusion method (Liofilchem, Abruzzo, Italy) on Mueller-Hinton agar plates complemented with $5 \%$ defibrinated horse blood and $20 \mathrm{mg} / \mathrm{L} \beta$ NAD (MH-F), based on EUCAST laboratory standards. ${ }^{44}$ The following antibiotic disks were used: benzyl-penicillin (1 IU; susceptibility to $\beta$-lactams was inferred from this test), erythromycin $(15 \mu \mathrm{g})$, clindamycin $(2 \mu \mathrm{g})$, norfloxacin (10 $\mu \mathrm{g}$; susceptibility to quinolones was inferred from this test), trimethoprim-sulfamethoxazole (1.25-23.75 $\mu \mathrm{g})$, tetracycline $(30 \mu \mathrm{g})$, vancomycin $(5 \mu \mathrm{g})$ and linezolid (10 $\mu \mathrm{g})$. Inducible clindamycin resistance was detected using the erythromycin-clindamycin D test; these strains were also reported as resistant to clindamycin. Interpretation of results was carried out using EUCAST clinical breakpoints. ${ }^{44}$ During data analysis, intermediately susceptible results were grouped with and reported as resistant. Streptococcus pneumoniae ATCC 49619 was used as a quality control strain.

\section{Statistical Analysis}

Statistical analyses, including the descriptive analysis (means or medians with ranges and percentages to characterize data) and statistical tests ( $X^{2}$-tests) were performed with IBM SPSS Statistics for Windows 24.0 
(IBM Corp., Armonk, NY, USA). P values $<0.05$ were considered statistically significant.

\section{Ethical Considerations}

Our research complies with the Declaration of Helsinki (1964) and its amendments. The study was deemed exempt from ethics review by the Institutional Review Board of the University of Szeged, as anonymity and the privacy of the patients was maintained during data collection and the collected data were handled confidentially. Informed consent was not required due to the retrospective nature of the review. Data on the epidemiology of scarlet fever were freely available from the National Bacteriological Surveillance database of the National Institute of Public Health; therefore, no approval was required for their use.

\section{Results}

\section{Epidemiology of GAS/GCGS Isolates}

\section{Throughout the Study Period}

Over the 10-year study period (January 2008 through December 2017), 1554 cases of streptococcal tonsillopharyngitis and 1104 cases of invasive streptococcal infections were detected (Table 1). Tonsillo-pharyngitis cases were predominantly caused by GAS $(95.5 \%$; $n=1484)$, with $148.4 \pm 31.9$ cases/year (ranging between 108 cases, ie, 26.5/100,000 persons in 2009, and 216 cases, ie, 44.1/ 100,000 persons in 2010), GCGS corresponded to a minority of pharyngitis cases $(4.5 \% ; n=70)$, with $8.0 \pm 3.6$ cases/year (ranging between 1 case, ie, $0.2 / 100,000$ persons in 2011, and 12 cases, ie, 2.9/100,000 cases in 2012). Similarly, GAS were the more common pathogens in invasive infections as well; however, their dominance was not as pronounced as in pharyngitis. GAS isolates constituted $77.9 \%(\mathrm{n}=861)$, with $84.0 \pm 26.5$ cases/year (ranging between 51 cases, ie, 12.5/ 100,000 persons in 2016, and 128 cases, ie, $31.4 / 100,000$ persons in 2011). GCGS isolates were relevant in $22.1 \%(n=243)$ of cases, with $22.6 \pm 18.9$ cases/year (ranging between 3 cases, ie, $0.73 / 100,000$ persons in 2010, and 50 cases, ie, 12.3/ 100,000 persons in 2014) (Table 1). The annual distribution of GAS/GCGS isolates causing tonsillo-pharyngitis and invasive infections is presented in Figures $1-4$. The incidence and rate of pGAS and pGCGS isolates was relatively constant between 2012 and 2017 (Figures 1 and 2). The incidence of iGAS reached a peak in 2011, while a steady decrease was

Table I Epidemiology, Age and Gender-Distribution of Group A and Group C/G Streptococcal Infections Causing Pharyngitis and Invasive Infections, 2008-2017

\begin{tabular}{|c|c|c|c|c|c|}
\hline Factor & Group & iGAS & iGCGS & Sum & Statistics* \\
\hline Study years & $\begin{array}{l}\text { Overall } \\
2008-2012 \\
2013-2017\end{array}$ & $\begin{array}{l}\mathrm{N}=86 \mathrm{I} \\
517(91.1 \%) \\
344(65.3 \%)\end{array}$ & $\begin{array}{l}N=243 \\
50(8.9 \%) \\
193(34.7 \%)\end{array}$ & $\begin{array}{l}N=1104 \\
567(100 \%) \\
537(100 \%)\end{array}$ & $\begin{array}{l}\mathrm{P}<0.000 \text { I } \\
\left(X^{2}=26.29, \text { DOF: I }\right)\end{array}$ \\
\hline Age group & $\begin{array}{l}\text { Overall } \\
0-17 \text { years } \\
18 \text { years and older }\end{array}$ & $\begin{array}{l}N=861 \\
54(37.2 \%) \\
807(84.1 \%)\end{array}$ & $\begin{array}{l}N=243 \\
91(62.8 \%) \\
I 52(15.9 \%)\end{array}$ & $\begin{array}{l}N=1104 \\
145(100 \%) \\
959(100 \%)\end{array}$ & $\mathrm{p}<0.000 \mid\left(X^{2}=|6| .46\right.$, DOF: 1$)$ \\
\hline Sex (all ages) & $\begin{array}{l}\text { Overall } \\
\text { Male } \\
\text { Female }\end{array}$ & $\begin{array}{l}N=861 \\
536(78.7 \%) \\
325(76.8 \%)\end{array}$ & $\begin{array}{l}\mathrm{N}=243 \\
\mid 45(2 \mid .3 \%) \\
98(23.2 \%)\end{array}$ & $\begin{array}{l}N=I 104 \\
68 I(100 \%) \\
423(100 \%)\end{array}$ & $\begin{array}{l}\mathrm{p}>0.05 \\
\left(X^{2}=0.53, \text { DOF: I }\right)\end{array}$ \\
\hline Factor & Group & pGAS & pGCGS & Overall & Statistics* \\
\hline Study years & $\begin{array}{l}\text { Overall } \\
2008-2012 \\
2013-2017\end{array}$ & $\begin{array}{l}N=1484 \\
788(95.9 \%) \\
696(93.7 \%)\end{array}$ & $\begin{array}{l}N=70 \\
23(4.1 \%) \\
47(6.3 \%)\end{array}$ & $\begin{array}{l}N=I 554 \\
81 I(100 \%) \\
743(100 \%)\end{array}$ & $\begin{array}{l}\mathrm{P}=0.039 \\
\left(X^{2}=4.27, \text { DOF: I }\right)\end{array}$ \\
\hline Age group & $\begin{array}{l}\text { Overall } \\
0-17 \text { years } \\
18 \text { years and older }\end{array}$ & $\begin{array}{l}\mathrm{N}=1484 \\
\mathrm{I} \mid 72(96.7 \%) \\
312(9 \mid .2 \%)\end{array}$ & $\begin{array}{l}N=70 \\
40(3.3 \%) \\
30(8.8 \%)\end{array}$ & $\begin{array}{l}N=1554 \\
1212(100 \%) \\
342(100 \%)\end{array}$ & $\begin{array}{l}\mathrm{P}<0.000 \mathrm{I} \\
\left(X^{2}=18.56, \text { DOF: I }\right)\end{array}$ \\
\hline Sex (all ages) & $\begin{array}{l}\text { Overall } \\
\text { Male } \\
\text { Female }\end{array}$ & $\begin{array}{l}N=1484 \\
808(96.9 \%) \\
676(93.8 \%)\end{array}$ & $\begin{array}{l}N=70 \\
25(3.1 \%) \\
45(6.2 \%)\end{array}$ & $\begin{array}{l}N=1554 \\
833(100 \%) \\
721(100 \%)\end{array}$ & $\begin{array}{l}\mathrm{P}=0.002 \\
\left(X^{2}=9.43, \text { DOF: I }\right)\end{array}$ \\
\hline
\end{tabular}

Note: *Statistical comparison of the two sub-groups (study years, age groups and sex).

Abbreviation: DOF, degrees of freedom. 


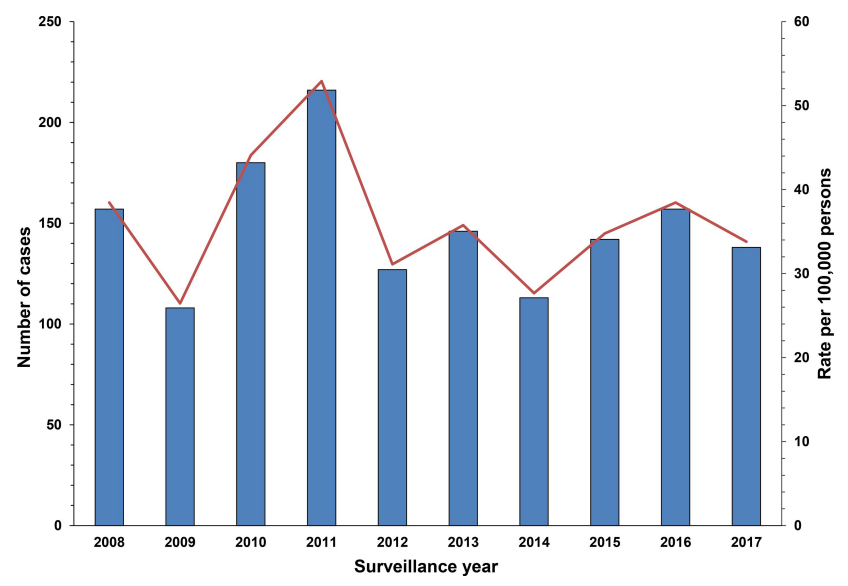

Figure I Incidence and rates of pGAS isolates during the study period, 2008-20I7.

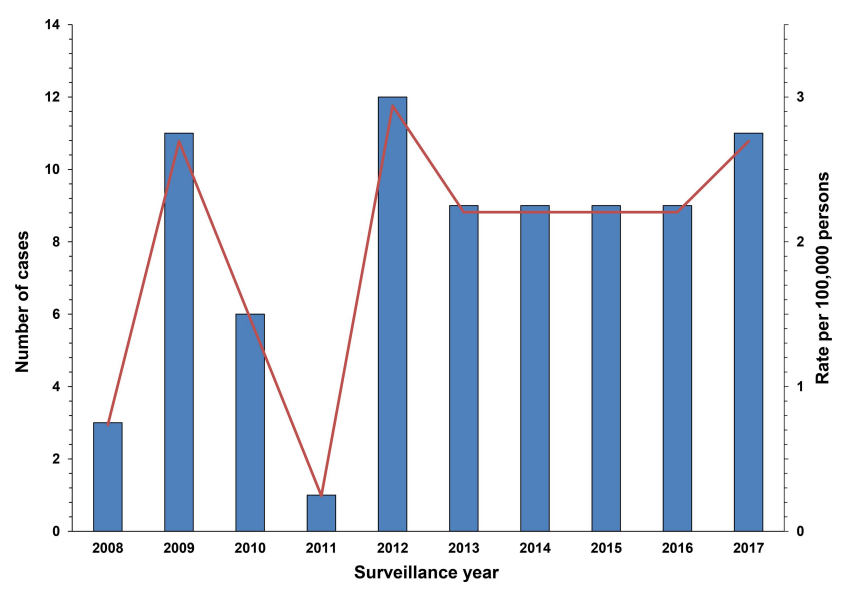

Figure 2 Incidence and rates of pGCGS isolates during the study period, 2008-2017.

seen, beginning from 2012 (Figure 3); on the other hand, the incidence of iGCGS isolates increased continuously throughout the study period (Figure 4) pGCGS and iGCGS isolates were statistically more common in the second half (20132017) of the study period. Statistically significant differences were observed based on sex (pGCGS were more frequent in females) and age (pGCGS were more frequent in patients aged $0-17$ years) (Table 1).

Seasonal variation was observed in the incidence of both types of streptococcal infections: pGAS was most common in the period between December and February $(35.0 \%)$, while the peak of pGCGS was seen a bit later, between January and March (29.5\%). Peak incidence of iGAS infections were also detected between December and February (31.7\%), with a smaller peak during summer months (June-August; 18.4\%). In contrast, the incidence of iGCGS showed a peak during summer months (JuneAugust; $33.2 \%$ ), while a winter peak was not observed. To

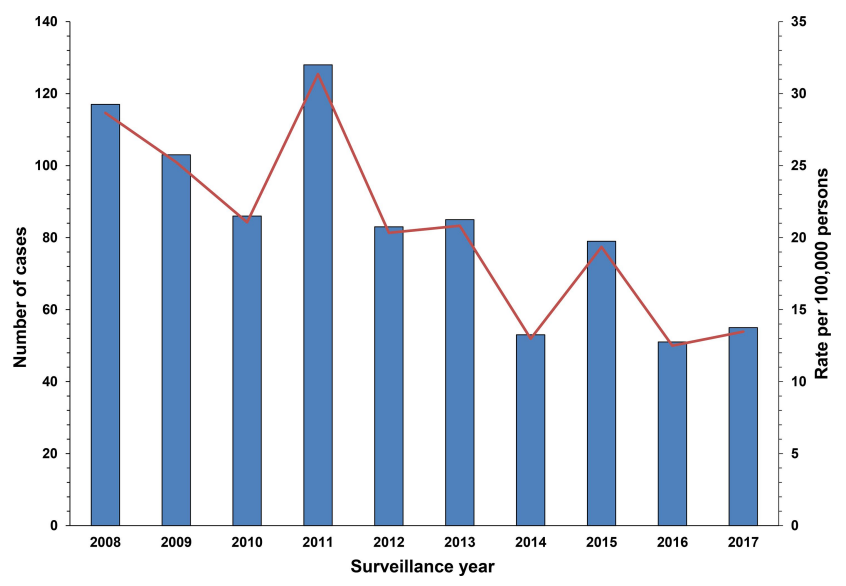

Figure 3 Incidence and rates of iGAS isolates during the study period, 2008-2017.

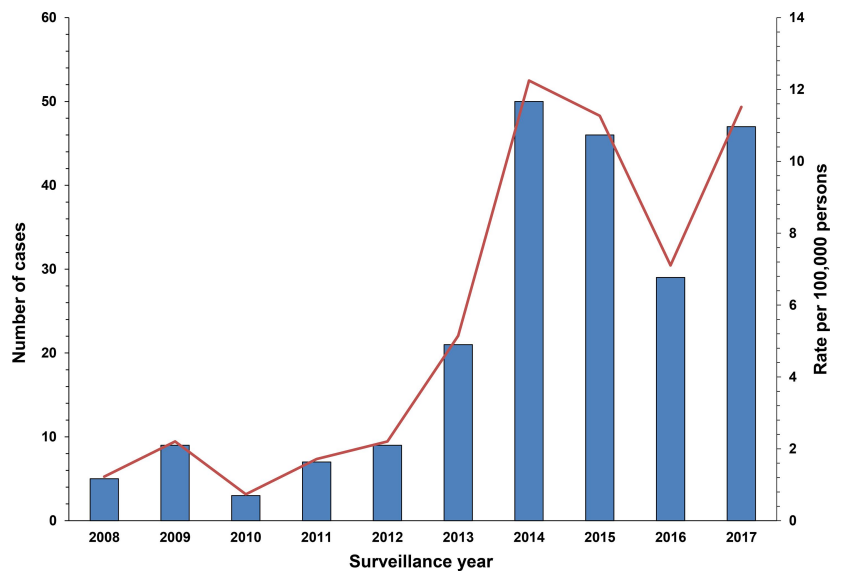

Figure 4 Incidence and rates of iGCGS isolates during the study period, 2008-2017.

put our local results in a national context, the incidence of GAS and GCGS infections was compared to the incidence of scarlet fever between 2008 and 2017: the average number of scarlet fever cases in Hungary was 2972.2 \pm 617.2 / year (ranging between 2356 cases, ie, 24.1/100,000 persons in 2009, and 4411 cases, ie, 45.1/100,000 persons in 2017).

The average age of the affected patients in the various groups was the following: pGAS: $13.2 \pm 13.1$ years and pGCGS: $21.0 \pm 15.0$ years $(p=0.039)$, iGAS: $49.1 \pm 12.8$ years and iGCGS: $58.7 \pm 18.5$ years $(\mathrm{p}>0.05)$. The distribution of GAS/GCGS isolates causing pharyngitis and invasive infections among patients $0-17$ years and in adult patients is presented in Table 1.

iGAS isolates originated from abscesses (47.1\%), blood culture samples $(24.1 \%)$, surgical samples $(16.7 \%)$, biopsies $(4.6 \%)$, pleural fluid $(3.5 \%)$, pus $(2.0 \%)$, synovial fluid $(1.3 \%)$ and CSF samples $(0.7 \%)$. In contrast, iGCGS 
isolates mainly originated from blood culture samples (53.8\%), abscesses (22.9\%), surgical samples (12.3\%), synovial fluid $(5.1 \%)$, pleural fluid $(3.7 \%)$, pus $(1.8 \%)$ and CSF samples $(0.4 \%)$.

\section{Antibiotic Resistance of GAS/GCGS Isolates Throughout the Study Period}

The susceptibility-testing results of GAS and GCGS isolates over the 10-year study period are presented in Table 2. All respective isolates were susceptible to benzyl-penicillin (ie, all $\beta$-lactam antibiotics), tetracycline (ie, also susceptible to doxycycline, minocycline, tigecycline), vancomycin and linezolid. Nevertheless, overall resistance levels of erythromycin (10.5\% for GAS, $21.4 \%$ for GCGS) and clindamycin (9.2\% for GAS, $17.2 \%$ for GCGS) were significantly higher in GCGS isolates, while resistance levels for norfloxacin (ie, fluoroquinolone antibiotics) were higher in Group A isolates (13.5\% for GAS, $6.9 \%$ for GCGS). There were no statistically significant differences seen in the resistance levels of GAS and GCGS isolates between the 2008-2012 and 2013-2017 time periods (data not shown).

\section{Discussion}

A total of 1554 cases of streptococcal tonsillo-pharyngitis and 1104 cases of invasive streptococcal infections were noted in Southern Hungary; although the majority of isolates still belonged to GAS, the steady increase in the isolation rates of GCGS isolates were shown in Southern Hungary, which is consistent with the worldwide reports (GCS: $2-7 \%$, GGS: $0.1-2.5 \%$ ), showing an increase in the GCS/GGSrelated disease burden. Although the incidence of iGCGS isolates were proportionally higher in patients aged 18 and older, pronounced epidemiological differentiation towards adult patients, similar to what has been shown in previous reports in the literature; in contrast, this tendency was not verified for pGCGS isolates whatsoever. Nonetheless, resistance levels were consistently higher in GCGS isolates (with the exception of quinolones), with has been noted in previous publications. Although many international studies from the last 5-10 years have noted the increase in the isolation frequency of GCGS isolates (which occurred from 2013 in our local settings), this coincided with the introduction of the MALDI-TOF MS in routine diagnostics. It is unclear whether this increase reflects true epidemiological changes (associated with the ageing population and the higher number of patients with risk factors for iCGCS infections) or rather, a technical change in diagnostics - which may have also distorted the results of other studies reporting an increased incidence. ${ }^{4,27,37,38,41}$ As there are no other reports available from the other regions of Hungary, it is also hard to ascertain the possible role of a geographical component.

Although the majority of GAS and GCS/GGS isolates remain exquisitely sensitive to penicillin in vitro, ${ }^{45}$ the clinical management of severe, invasive $\beta$-haemolytic streptococcal infections remain challenging. ${ }^{46}$ While penicillin is still considered as the first-choice drug for uncomplicated streptococcal infections, they have been proven ineffective in invasive infections. ${ }^{47}$ In fact, based on the recommendations of the Infectious Diseases Society of America, penicillin should be used in combination with a protein synthesis inhibitor (eg, clindamycin) in these clinical cases. $^{48}$ The use of clindamycin for lifethreatening invasive infections was shown to reduce mortality rates. ${ }^{49}$ Patients with penicillin-allergy (where these patients may also have cross-reactions with cephalosporins and carbapenems) must also be considered during the

Table 2 Antibiotic Resistance Levels of Group A and Group C/G Streptococcal Infections Causing Pharyngitis and Invasive Infections, 2008-2017

\begin{tabular}{|c|c|c|c|c|c|c|c|}
\hline & \multicolumn{3}{|l|}{ GAS } & \multicolumn{3}{|l|}{ GCGS } & \multirow[t]{2}{*}{ Statistics* } \\
\hline & pGAS & iGAS & Overall & pGCGS & iGCGS & Overall & \\
\hline Benzyl-penicillin & $0(0 \%)$ & $0(0 \%)$ & $0(0 \%)$ & $0(0 \%)$ & $0(0 \%)$ & $0(0 \%)$ & - \\
\hline Erythromycin & 146 (9.8\%) & $100(11.6 \%)$ & $246(10.5 \%)$ & $15(21.4 \%)$ & $52(21.4 \%)$ & $67(21.4 \%)$ & $\mathrm{p}<0.0001 \quad\left(X^{2}=31.69\right.$, DOF: I $)$ \\
\hline Clindamycin & 118 (7.9\%) & 98 (11.4\%) & $216(9.2 \%)$ & $14(20.0 \%)$ & $40(14.6 \%)$ & 54 (I7.2\%) & $\mathrm{p}<0.000 \mathrm{I}\left(X^{2}=19.56\right.$, DOF: 1$)$ \\
\hline Trimethoprim-sulfamethoxazole & $48(3.2 \%)$ & $25(2.9 \%)$ & $73(3.1 \%)$ & $0(0 \%)$ & $\mathrm{I}(0.4 \%)$ & $\mathrm{I}(0.2 \%)$ & $\mathrm{p}=0.005\left(X^{2}=7.96\right.$, DOF: I $)$ \\
\hline Norfloxacin & 199 (13.4\%) & $117(13.6 \%)$ & $316(13.5 \%)$ & $4(5.7 \%)$ & $13(7.4 \%)$ & $17(6.9 \%)$ & $\mathrm{p}<0.0001\left(X^{2}=16.31, \mathrm{DOF}: \mathrm{I}\right)$ \\
\hline Tetracycline & $0(0 \%)$ & $0(0 \%)$ & $0(0 \%)$ & $0(0 \%)$ & $0(0 \%)$ & $0(0 \%)$ & - \\
\hline Vancomycin & $0(0 \%)$ & $0(0 \%)$ & $0(0 \%)$ & $0(0 \%)$ & $0(0 \%)$ & $0(0 \%)$ & - \\
\hline Linezolid & $0(0 \%)$ & $0(0 \%)$ & $0(0 \%)$ & $0(0 \%)$ & $0(0 \%)$ & $0(0 \%)$ & - \\
\hline
\end{tabular}

Note: *Statistical comparison of resistance levels among GAS and GCGS isolates overall.

Abbreviation: DOF, degrees of freedom. 
choice of therapy. ${ }^{50,51}$ In case of patients with penicillin allergy, macrolides, lincosamides and fluoroquinolones are considered as relevant therapeutic alternatives. ${ }^{52}$ However, one of the most concerning developments include the description of penicillin-resistance in boh $\mathrm{GAS}^{53}$ and $\mathrm{SDSE}^{54}$ isolates, linked to a $p b p 2 x$ mutation; additionally, a report provided evidence of a large clonal population of GAS with sub-clinical $\beta$-lactam tolerance (associated with a similar $p b p 2 x$ mutation) in Iceland. ${ }^{55}$

Based on the data mentioned above, the relevance of protein-synthesis inhibitor antibiotics in the therapy of these infections should be stressed further. Increased resistance in GAS and GCS/GGS isolates towards macrolides and clindamycin has been reported in many countries, eg, macrolide-resistance in GAS was shown to be $22.8 \%$ in Greece, 32.8\% in Spain, 40\% in Bulgaria and Belgium and may be as high as $95 \%$ in China. ${ }^{56}$ The steady increase in resistance was demonstrated in the US, where erythromycin/clindamycin resistance was $14 / 13 \%$ in $2015,16 / 15 \%$ in 2016 and $23 / 22 \%$ in 2017, respectively (based on the CDC database). In addition, erythromycin-resistant GAS was associated with 5400 cases and 450 extra deaths in 2017. Macrolide resistance is either mediated by target site modification (rRNA methylases; the expression of which may be constitutive [cMLS] or inducible [iMLS]) or the overexpression of efflux pumps (mefA gene) and is related to the $\mathrm{M}$ phenotype. ${ }^{56,57}$ Currently, emm cluster typing (which groups emm types into 48 different clusters on the basis of their structural properties of the M protein). ${ }^{58}$ Similar to the emergence of fluoroquinoloneresistant $S$. pneumoniae, resistant GAS isolates are also increasingly reported; the main mechanism associated with these isolates are the mutations of $g y r A$ and parC genes. ${ }^{59}$ The emergence of resistance in GAS has been associated with the extensive use of relevant antibiotics in the country. ${ }^{60}$ When it comes to antibiotic consumption, Hungary is among the countries with low consumption levels quantitatively; however, consumption levels of macrolides, lincosamides and streptogramins (J01F; 2.8 defined daily doses/1000 inhabitants per day) and quinolones (J01M; 2.3 defined daily doses/1000 inhabitants per day) in the country is among the highest in Europe. ${ }^{61}$ This phenomenon may explain the rate of resistance in Southern Hungary in GAS and GCS/GGS isolates.

In the following section, a concise summary of the most relevant epidemiological studies will be presented to put our results in context with findings in the international literature. In a study by Ekelund et al in Denmark, GAS infections were the most numerous (40\%) among invasive infections between 1999 and 2002, followed by GGS (32\%), GBS $(23 \%)$ and GCS $(6 \%)$. The overall mortality in this study was $21 \%$, with most of the GCS/GGS affecting patients (74\%) with predisposing factors. ${ }^{37}$ Later on, a nationwide study by Lambertsen et al between 2005 and 2011 pointed out the increase in the incidence of laboratory-confirmed GAS, GBS, GCS and GGS infections (3.1, 2.3, 0.9 and 2.6 per 100000 persons, respectively), compared to the previous study. ${ }^{62}$ Zaoutis et al reported the incidence of GCS/GGS in acute pharyngitis over a 12-month period in Philadelphia, USA: $17.7 \%$ of pharyngitis cases were nonGAS, and the average age of patients was 6 years. $^{63}$ In a prospective study by Steer et al, the epidemiology of invasive GAS over a 2-year period in Fiji was assessed; allage incidence was 9.9 cases/100,000 population per year, while the case-fatality rate was $32.0 \%$. In addition, they have shown that invasive GAS infections were the most common in patients over 65 years of age. ${ }^{5}$ In a Spanish study by Montes et al, the prevalence of GAS isolates was studied during 1998-2009; ${ }^{64}$ incidence of invasive disease was 3.1 for children and 1.9 for adults per 100,000 inhabitants, and $17 \%, 8.9 \%$ and $13 \%$ of isolates were resistant to erythromycin, ciprofloxacin and tetracycline, respectively. ${ }^{64}$ Invasive GAS infections were assessed in Germany between 2003 and 2007 by Imöhl et al; ${ }^{65}$ out of $n=586$ isolates, susceptibility to penicillin $\mathrm{G}$ and levofloxacin was $100 \%$, while resistance to tetracycline, clarithromycin and clindamycin was $11.6 \%, 5.5 \%$ and $1.2 \%$. Clinical manifestations included sepsis $(40.1 \%)$, necrotizing fasciitis $(20.8 \%)$ and streptococcal toxic shock syndrome $(16.6 \%){ }^{65}$ Darenberg et al provided epidemiological results for invasive GAS infections for Sweden corresponding to 2002-2004. ${ }^{66}$ The incidence was 3.0 cases per 100,000 population, $11 \%$ of the patients developed TSS, while 9.5\% developed necrotizing fasciitis; the overall mortality rate was $14.5 \%$. Ho et al assessed the resistance levels of invasive and non-invasive GAS isolates between 1995 and $1998 ;{ }^{67}$ resistance levels to erythromycin and tetracycline were high $(32 \%$ and $53 \%)$. Rantala et al provided a population-based study, corresponding to the period between 1995 and 2004, during which 18 cases of GCS and 128 GGS bacteremia were identified. ${ }^{68}$

Harris et al carried out a 14-year-long study in Australia, assessing bacteraemia caused by beta-haemolytic streptococci: GAS isolates were the most common (49\%), with GCS/GGS isolates showing a modest, but significant, increase over time. Significant differences were no observed 
in the mortality rates between the different beta-haemolytic streptococci infections. ${ }^{69}$ Wong et al reported $n=73$ invasive GGS infections in a New York community hospital over a 5-year period; the mean age of patients was 53 years, and the average length of stay for all patients with GGS was 9.4 days, with longer stays for those with underlying diabetes mellitus (14.6 days). ${ }^{70}$ Bruun et al studied the incidence of GCS/GGS necrotizing soft tissue infections in Norway (2000-2009): ${ }^{71}$ they have reported a mean annual incidence rate of 1.4 per 100 000, with a mortality rate of $33 \%$, compared to $11 \%$ in the GAS group. Hashikawa et al characterized GCS/GGS causing toxic shock syndrome (STSS) in Japan, finding that all STSS-causing isolates had a close genetic relationship. ${ }^{72}$ Slyvetsky et al showed that $15 \%$ of bacteremia caused by $\beta$-hemolytic Streptococcus was GGS, with a mortality rate of $15 \%{ }^{35}$ Loubinoux et al characterized $n=182$ isolates of SDSE from invasive and noninvasive infections between 2006 and 2010; resistance to macrolides was $26.4 \%$, while resistance to tetracycline was $34.6 \%$. $^{73}$

During a 15-year-long surveillance period, Oppegaard et $\mathrm{al}^{38}$ assessed the incidence of invasive and non-invasive GAS, GCS and GGS isolates in Western Norway: the distribution of invasive isolates was 58\% GAS, 5\% GCS and $37 \%$ GGS, respectively. The incidence of all isolates increased with patient age, a male dominance was observed, and a seasonal variation was shown, similarly to our study. The incidence of invasive GCGS infections increased from 1.4 to 6.3 per 100,000 persons from the beginning to the end of the study period, while GAS infections showed marked fluctuations (2.7-8.3 per 100,000 persons). ${ }^{38}$ As a part of the Arctic Investigations Program (AIP), Rudolph et al surveyed the incidence of invasive GAS infections in Alaska between 2001 and 2013. ${ }^{41}$ Resistance to tetracycline, erythromycin, and clindamycin were relatively low $(11.0 \%, 5.8 \%$ and $1.2 \%$, respectively) with an observed incidence of 5.8 cases per 100,000 persons; the mortality rate was $10.7 \%$, overall. In a large collaborative study (by the Strep-EURO Study Group) involving 11 European countries, the emergence of severe S. pyogenes infections was surveyed between 2003 and $2004 ;^{74}$ the reported incidence was $3 / 100,000$ population, which higher incidences in the northern European countries, while the 7-day mortality rate was $19 \%$ (44\% for patients with STSS). This European study has also highlighted the seasonal variation in invasive GAS infections, which coincided in almost all participating countries. The epidemiology of invasive GAS infections was assessed on a national level by the CDC: between 2000 and 2004, the incidence was 3.5 cases $/ 100,000$ persons with an overall mortality rate of $13.7 \%$ (36.0\% for STSS and $24.0 \%$ for necrotizing fasciitis). ${ }^{75}$ The continuation of this study in 2005-2012 saw a slight increase in overall incidence (3.8 cases/100,000 persons) and a decrease in mortality rate (11.7\%; mortality rate in patients aged 65 and over: 9.4/ $100000) .{ }^{76} \mathrm{M}$ typing and the molecular characterization of resistance-determinants in a national setting has important public health implications; nevertheless, there is a scarcity of data on the molecular epidemiology of streptococci in Hungary. This scarcity was not improved by the fact that Hungary was not among the participating members of the Strep-EURO group study. ${ }^{77}$ The most recent data available are from the early 2000s: Gattringer et al characterized $\mathrm{n}=191 S$. pyogenes isolates originating from Hungary. In their report, $3.7 \%$ of the isolates were resistant to macrolides (mainly due to mefA and erm TR genes) and $30.5 \%$ were resistant to tetracycline (the large volume of prophylactic tetracycline use may have contributed to this rate). ${ }^{78}$ Additionally, Krucsó et al characterized $n=26$ invasive GAS isolates from Hungary with molecular biological methods during 2004-2005: the following emm types were the most numerous: emm 1 (50\%), emm80 (19.2\%); however, other $\mathrm{M}$ types were also described in these isolates (emm4, emm28, emm66, emm81.1, emm82 and emm84). ${ }^{79}$

\section{Limitations of the Study}

Some limitation of our study should be addressed: i) the study design is retrospective and there was scarce clinical data available due to the inability to access the medical records of the individual patients. ii) for this reason, the association of relevant risk factors, underlying illnesses (apart from age and inpatient/outpatient status) and studies infections could not be performed (however, attempts were made to discard/exclude isolates with little or no clinical relevance). iii) our study is subject of selection bias, ie, it reports the results from a tertiary-care hospital, corresponding to patients with more severe conditions or underlying illnesses. iv) the CDC has recently identified SDSE isolates containing Group A antigens; as the uncertainty of misidentification regarding the presence of such isolates could not be excluded using our methods, this must also be noted as a limitation. v) data on emm typing or M typing could have strengthened the relevance of our results in an international context; however, due to the prolonged study period, lacking technical capabilities, monetary constraints 
and the overwhelming number of isolates to be tested, our study did not include this. vi) the molecular characterization of resistance determinants (eg, macrolide, quinolone resistance) in the individual isolates and erm typing were not performed as a part of this study for reasons mentioned in point $\mathrm{v}$ ).

\section{Conclusions}

In our study, the epidemiology and resistance levels were assessed among Groups A, C and G $\beta$-haemolytic streptococci in Southern Hungary, over a long surveillance period. While there was undoubtedly an increase in the isolation rate of GCGS isolates, associations with patients characteristics are still unclear. The rates of resistance to macrolides and clindamycin are a cause for concern (especially among GCGS isolates); however, resistance levels are still relatively low, compared to Southern European countries. Due to the constant burden of $\beta$-haemolytic streptococcal diseases, the continuous surveillance of GAS and GCGS infections in both tonsillo-pharyngitis and in invasive infections is warranted.

\section{Data Sharing Statement}

All data generated during the study is presented in this paper.

\section{Author Contributions}

All authors made substantial contributions to conception and design, acquisition of data, or analysis and interpretation of data; took part in drafting the article or revising it critically for important intellectual content; agreed to submit to the current journal; gave final approval of the version to be published; and agree to be accountable for all aspects of the work.

\section{Funding}

The article processing charge (APC) was funded by the University of Szeged Open Access fund (ID: 4946). M. G. was supported by the János Bolyai Research Scholarship (BO/00144/20/5) of the Hungarian Academy of Sciences. The research was supported by the ÚNKP-205-SZTE-330 New National Excellence Program of the Ministry for Innovation and Technology from the source of the National Research, Development and Innovation Fund. Support from Ministry of Human Capacities, Hungary grant 20391-3/2018/FEKUSTRAT is acknowledged. M.G. would also like to acknowledge the support of ESCMID's “30 under 30” Award.

\section{Disclosure}

The authors declare no conflict of interest, monetary or otherwise. The authors alone are responsible for the content and writing of this article.

\section{References}

1. Sktkiewicz I, Hryniewicz W. Pyogenic streptococci-danger of reemerging pathogens. Pol J Microbiol. 2010;59:219-226. doi:10.33073/pjm-2010-034

2. Janda WM, Stroger JH. The genus streptococcus part I emerging pathogens in the "Pyogenic Cocci" and the "Streptococcus Bovis" groups. Clin Microbiol Newslett. 2014;36:157-166. doi:10.1016/j. clinmicnews.2014.10.001

3. Facklam R. What happened to the streptococci: overview of taxonomic and nomenclature changes. Clin Microbiol Rev. 2002;15:613-630.

4. Gajdács M. Taxonomy and nomenclature of bacteria with clinical and scientific importance: current concepts for pharmacists and pharmaceutical scientists. Acta Pharm Hung. 2019;89:99-108. doi:10.33892/ aph.2019.89.99-108

5. Steer AC, Jenney A, Kado J, Good MF, Batzloff M, Waqatakirewa L, Mullholland EK, Carapetis JR. Prospective surveillance of invasive Group A streptococcal disease, Fiji, 2005-2007.Emerg Infect Dis2009;15;216-222.

6. Hryniewicz W, Heczko PB, Lütticken R, Wannamaker LW. Comparison of three methods for grouping Streptococci. J Clin Microbiol. 1976;4:28-31.

7. Tagini F, Aubert B, Troillet N, et al. Importance of whole genome sequencing for the assessment of outbreaks in diagnostic laboratories: analysis of a case series of invasive Streptococcus pyogenes infections. Eur J Clin Microbiol Infect Dis. 2017;36:1173-1180. doi:10.1007/s10096-017-2905-z

8. Babbar A, Itzek A, Pieper DH, Nitsche-Schmitz DP. Detection of Streptococcus pyogenes virulence genes in Streptococcus dysgalactiae subsp. equisimilis from Vellore, India. Folia Microbiol. 2018;63:581-586. doi:10.1007/s12223-018-0595-2

9. Shannon BA, McCormick JK, Schievert PM. Toxins and superantigens of group A streptococci. Gram-Positive Pathogens. 2018;55-66. doi:10.1128/microbiolspec.GPP3-0054-2018

10. Šmitran A, Vuković D, Opavski N, et al. Influence of subinhibitory antibiotic concentration on Streptococcus pyogenes adherence and biofilm production. Acta Microbiol Immunol Hung. 2018;653:229-240. doi:10.1556/030.65.2018.026

11. Klos M, Wójkowska-Mach J. Pathogenicity of virulent species of group C streptococci in human. Can J Infect Dis Med Microbiol. 2017;2017:9509604. doi:10.1155/2017/9509604

12. Oliver J, Malliya Wadu E, Pierse N, Moreland NJ, Willamson DA, Baker MG. Group A Streptococcus pharyngitis and pharyngeal carriage: a meta-analysis. PLoS One. 2018;12:e006335. doi:10.1371/ journal.pntd.0006335

13. Speert DP. Group A streptococcal carriage can the troll be tamed?. Paediatr Child Health. 1998;3:229-230. doi:10.1093/pch/3.4.229

14. Brandt CM, Spellerberg B. Human infections due to Streptococcus dysgalactiae subspecies equisimilis. Clin Infect Dis. 2009;49:766-772. doi:10.1086/605085

15. Nelson GE, Pondo T, Toews KA, et al. Epidemiology of invasive group A streptococcal infections in the United States, 2005-2012. Clin Infect Dis. 2016;63:478-486. doi:10.1093/cid/ciw248

16. Martin JM. The mysteries of streptococcal pharyngitis. Cur Treat Opinions Pediatr. 2015;1:180-189. doi:10.1007/s40746-015-0013-9

17. Basetti S, Hodgson J, Rawson TM, Majeed A. Scarlet fever: a guide for general practitioners. London J Prim Care (Abingdon). 2017;9:77-79. doi:10.1080/F17571472.2017.1365677 
18. Kuriyan AE, Weiss KD, Flynn HW, et al. Endophthalmitis caused by streptococcal species: clinical settings, microbiology, management, and outcomes. Am J Ophthalmol. 2014;157:744-780. doi:10.1016/j. ajo.2013.12.026

19. Harris CM, Johnikin M, Rhodes H, et al. Lemierre's syndrome resulting from streptococcal induced otitis media and mastoiditis: a case report. J Med Case Reports. 2009;3:e6658. doi:10.1186/ 1752-1947-3-6658

20. Dubost JJ, Soubrier M, De Champs C, Ristori JM, Sauvezie B. Streptococcal septic arthritis in adults. A study of 55 cases with a literature review. Joint Bone Spine. 2004;71:303-311. doi:10.1016/S1297-319X(03)00122-2

21. Ibia O, Imoisili M, Pikis A. Group A beta-hemolytic streptococcal osteomyelitis in children. Pediatrics. 2003;112:e22-26. doi:10.1542/ peds.112.1.e22

22. Chelsom J, Halstensen A, Haga T, Hoiby EA. Necrotising fasciitis due to group A streptococci in Western Norway: incidence and clinical features. Lancet. 1994;344:1111-1115. doi:10.1016/S01406736(94)90629-7

23. Tanaka H, Katsuragi S, Hasegawa J, et al. The most common causative bacteria in maternal sepsis-related deaths in Japan were group A Streptococcus: a nationwide survey. $J$ Infect Chemother. 2019;25:41-44. doi:10.1016/j.jiac.2018.10.004

24. Hoge CW, Schwartz B, Talkington DF, Breiman RF, MacNeill EM, Englender SJ. The changing epidemiology of invasive group A streptococcal infections and the emergence of streptococcal toxic shock-like syndrome (1993) A retrospective population-based study. JAMA. 1993;269:384-389. doi:10.1001/ jama.1993.03500030082037

25. Fanella S, Embree J. Group A streptococcal meningitis in a pediatric patient. Can J Infect Dis Med Microbiol. 2008;19:306-308. doi: $10.1155 / 2008 / 594583$

26. Yung L, Rashid M, Brau N. Group C streptococcus dysgalactiae subsp.equisimilis (SDSE) endocarditis with endogenous endophthalmitis and aortic root abscess. IDCases. 2019;15:e0513. doi:10.1016/ j.idcr.2019.e00513

27. Ikebe $\mathrm{T}$, Okuno $\mathrm{R}$, Uchitani $\mathrm{Y}$, et al. $\mathrm{T}$ serotyping of group a streptococcus isolated from patients with pharyngitis or streptococcal toxic shock syndrome in Japan between 2005 and 2017. J Infect Chemother. 2020;26:157-161.

28. Cunningham MW. Pathogenesis of group A streptococci. Clin Microbiol Rev. 2000;13:470-491. doi:10.1128/CMR.13.3.470511.2000

29. Muhtarova A, Mihova K, Markovksa R, Mitov I, Kaneva R, Gergova R. Molecular emm typing of Bulgarian macrolide-resistant Streptococcus pyogenes isolates. Acta Microbiol Immunol Hung. 2019;66:1-4. doi:10.1556/030.66.2019.033

30. Burián K, Berencsi K, Endrész V, et al. Chlamydia pneumoniae exacerbates aortic inflammatory foci caused by murine cytomegalovirus infection in normocholesterolemic mice. Clin Vaccine Immunol. 2001;8:1263-1266.

31. Tatara K, Gotoh K, Okumiya K, et al. Molecular epidemiology, antimicrobial susceptibility, and characterization of fluoroquinolone non-susceptible Streptococcus pyogenes in Japan. $J$ Infect Chemother. 2020;26:280-284. doi:10.1016/j.jiac.2019.10.004

32. Carapetis JR, Steer AC, Mulholland EK, Weber M. The global burden of group A streptococcal diseases. Lancet Infect Dis. 2005;5:685-694. doi:10.1016/S1473-3099(05)70267-X

33. Baracco GJ. infections caused by group $\mathrm{C}$ and $\mathrm{G}$ streptococcus (streptococcus dysgalactiae subsp. equisimilis and others): epidemiological and clinical aspects. Gram-Positive Pathogens. 2019;275-283. doi:10.1128/microbiolspec.GPP3-0016-2018

34. Shahin VA, Saba M, Greene JN. A retrospective chart review on the clinical characteristics and outcomes of cancer patients with group $\mathrm{C}$, F, or G $\beta$-hemolytic streptococcal infections. Infect Dis Clin Pract. 2019;27:205-210. doi:10.1097/IPC.0000000000000723
35. Sylvetsky N, Raveh D, Schlesinger Y, Rudensky B, Yinnon AM. Bacteremia due to beta-hemolytic Streptococcus group G: increasing incidence and clinical characteristics of patients. $\mathrm{Am} \mathrm{J} \mathrm{Med}$. 2002;112:622-626. doi:10.1016/S0002-9343(02)01117-8

36. Meisal R, Høiby EA, Aaberge IS, Caugant DA. Sequence type and emm type diversity in Streptococcus pyogenes isolates causing invasive disease in Norway between 1988 and 2003. J Clin Microbiol. 2008;46:2102-2105. doi:10.1128/JCM.00363-08

37. Ekelund K, Skinhoj P, Madsen J, Konradsen HB. Invasive group A, B, C and G streptococcal infections in Denmark 1999-2002: epidemiological and clinical aspects. Clin Microbiol Infect. 2005;11:569-576. doi:10.1111/j.1469-0691.2005.01169.x

38. Oppegaard O, Hylvaganam H, Kittang BR. Beta-haemolytic group A, $\mathrm{C}$ and $\mathrm{G}$ streptococcal infections in Western Norway: a 15-year retrospective survey. Clin Microbiol Infect. 2015;21:171-178. doi:10.1016/j.cmi.2014.08.019

39. Gajdács M, Burián K, Terhes G. Resistance levels and epidemiology of non-fermenting gram-negative bacteria in urinary tract infections of inpatients and outpatients (RENFUTI): a 10-year epidemiological snapshot. Antibiotics. 2019;8:e143. doi:10.3390/antibiotics8030143

40. Hospital Bed Count and Patient Turnover Report. 2017. National health insurance fund of Hungary. Available from: http://www.neak. gov.hu/felso_menu/szakmai_oldalak/publikus_forgalmi_adatok/gyo gyito_megelozo_forgalmi_adat/fekvobeteg_szakellatas/korhazi_agys zam.html. Accessed May 15, 2020.

41. Rudolph K, Bruce MG, Bruden D, et al. Epidemiology of invasive group A streptococcal disease in Alaska, 2001 to 2013. J Clin Microbiol. 2016;54:134-141. doi:10.1128/JCM.02122-15

42. Jensen CS, Dam-Nielsen C, Arpi M. Matrix-assisted laser desorption/ ionization-time of flight mass spectrometry identification of large colony beta-hemolytic streptococci containing Lancefield groups A, C, and G. Infect Dis (London). 2015;47:575-579. doi:10.3109/ 23744235.2015.1043940

43. Balogh EP, Faludi I, Virók DP, Endrész V, Burián K. Chlamydophila pneumoniae induces production of the defensin-like MIG/CXCL9, which has in vitro antichlamydial activity. Int $J$ Med Microbiol. 2015;301:252-259. doi:10.1016/j.ijmm.2010.08.020

44. EUCAST Clinical Breakpoints and Dosing. Available from: https:// www.eucast.org/clinical_breakpoints/. Accessed May 15, 2020.

45. Camara M, Dieng A, Boye CSB. Antibiotic susceptibility of streptococcus pyogenes isolated from respiratory tract infections in Dakar, Senegal. Microbiol Insights. 2013;6:71-75. doi:10.4137/MBI.S12996

46. Parks T, Barrett L, Jones N. Invasive streptococcal disease: a review for clinicians. Brit Med Bulletin. 2015;115:77-89. doi:10.1093/bmb/ldv027

47. Allen UD, Moore DL. Invasive group A streptococcal disease: management and chemoprophylaxis. Paediatr Child Health. 2010;15:295-298. doi:10.1093/pch/15.5.295

48. Shulman ST, Bisno AL, Clegg HW, et al. Clinical practice guideline for the diagnosis and management of group A streptococcal pharyngitis: 2012 update by the infectious diseases society of America. Clin Infect Dis. 2012;55:e102. doi:10.1093/cid/cis847

49. Falagas ME, Matthaiou DK, Karveli EA, Peppas G. Meta-analysis: randomized controlled trials of clindamycin/aminoglycoside vs. $\beta$ lactam monotherapy for the treatment of intra-abdominal infections. Alimentary Pharmacol Ther. 2007;25:537-556. doi:10.1111/j.13652036.2006.03240.x

50. Castells M, Khan DA, Phillips EJ. Penicillin allergy. $N$ Engl J Med. 2019;381:2338-2351. doi:10.1056/NEJMra1807761

51. Gajdács M. Intravenous or oral antibiotic therapy: sophie's choice? Gen Int Med Clin Innov. 2019;4:1-2. doi:10.15761/GIMCI.1000176

52. Tarlow MJ. Macrolides in the management of streptococcal pharyngitis/tonsillitis. Pediatr Infect Dis J. 1997;16:444-448. doi:10.1097/00006454-199704000-00028

53. Vannice KS, Ricaldi J, Nanduri S, et al. Streptococcus pyogenes pbp2x mutation confers reduced susceptibility to $\beta$-lactam antibiotics. Clin Infect Dis. 2020;71:201-204. doi:10.1093/cid/ciz1000 
54. Fuursted K, Stegger M, Hoffmann S, et al. Description and characterization of a penicillin-resistant Streptococcus dysgalactiae subsp. equisimilis clone isolated from blood in three epidemiologically linked patients. $J$ Antimicrob Chemother. 2016;71:3376-3380. doi:10.1093/jac/dkw320

55. Southon SB, Beres SB, Kachroo P, et al. Population genomic molecular epidemiological study of macrolide-resistant Streptococcus pyogenes in Iceland, 1995 to 2016: identification of a large clonal population with a pbp $2 x$ mutation conferring reduced in vitro $\beta$ lactam susceptibility. $J$ Clin Microbiol. 2020;58:e00638-20. doi:10.1128/JCM.00638-20

56. Haenni M, Lupo A, Madec JY. Antimicrobial resistance in streptococcus spp. Antimicrobial Resistance in Bacteria from Livestock and Companion Animals. 2018;159-184. doi:10.1128/microbiolspec. ARBA-0008-2017

57. Schmitz FJ, Verhoef J, Fluit AC; The Sentry Participants Group. Prevalence of resistance to MLS antibiotics in 20 European university hospitals participating in the European SENTRY surveillance programme. $J$ Antimicrob Chemother. 1999;43:783-792. doi:10.1093/jac/43.6.783.

58. Grivea IN, Syrogiannopoulos GA, Muchoula AN, et al. emm Types and clusters and macrolide resistance of pediatric group A streptococcal isolates in Central Greece during 2011-2017. PLoS One. 2020;15:e0232777. doi:10.1371/journal.pone.0232777

59. Richter SS, Diekema DJ, Heilmann KP, et al. Fluoroquinolone resistance in streptococcus pyogenes. Clin Infect Dis. 2003;36:380-383. doi:10.1086/345904

60. Sayyahfar S, Fahimzad A, Naddaf A, Tavassoli S. Antibiotic susceptibility evaluation of group A streptococcus isolated from children with pharyngitis: a study from Iran. Infect Chemother. 2015;47:225-230. doi:10.3947/ic.2015.47.4.225

61. European Centre for Disease Prevention and Control. Antimicrobial consumption - Annual Epidemiological Report for 2018. Available online: https:/www.ecdc.europa.eu/en/publications-data/surveillanceantimicrobial-consumption-europe-2018. Accessed May 15, 2020.

62. Lambertsen LM, Ingels H, Sconheyder HC, Hoffmann S, Mainardi JL; Danish Streptococcal Surveillance Collaboration Group 2011. Nationwide laboratory-based surveillance of invasive beta-haemolytic streptococci in Denmark from 2005 to 2011. Clin Microbiol Infect. 2014;20:O216-O223. doi:10.1111/1469. 0691.12378

63. Zaoutis T, Attia M, Gross R, Klein J. The role of group C and group $\mathrm{G}$ streptococci in acute pharyngitis in children. Clin Microbiol Infect. 2002;10:37-40. doi:10.1111/j.1469-0691.2004.00732.x

64. Montes M, Ardanuy C, Tamayo E, Doménech A, Linares J, PérezTrallero E. Epidemiological and molecular analysis of Streptococcus pyogenes isolates causing invasive disease in Spain (1998-2009): comparison with non-invasive isolates. Eur J Clin Microbiol Infect Dis. 2011;30:e1295. doi:10.1007/s10096-011-1226-x

65. Imöhl M, Reniert RR, Ocklenburg C, van der Linden M. Epidemiology of invasive Streptococcus pyogenes disease in Germany during 2003-2007. Pathogens Dis. 2010;58:389-396. doi:10.1111/j.1574-695X.2010.00652.x

Infection and Drug Resistance

\section{Publish your work in this journal}

Infection and Drug Resistance is an international, peer-reviewed openaccess journal that focuses on the optimal treatment of infection (bacterial, fungal and viral) and the development and institution of preventive strategies to minimize the development and spread of resistance. The journal is specifically concerned with the epidemiology of
66. Darenberg J, Luca-Harari B, Jasin A, et al. Molecular and clinical characteristics of invasive group A streptococcal infection in Sweden. Clin Infect Dis. 2007;45:450-458. doi:10.1086/519936

67. Ho PL, Johnson DR, Yue AW, et al. Epidemiologic analysis of invasive and noninvasive group a streptococcal isolates in Hong Kong. $J$ Clin Microbiol. 2003;41:937-942. doi:10.1128/ jcm.41.3.937-942.2003

68. Rantala S, Vuopio-Varkila J, Vuento R, Huhtala H, Syrjanen J. Clinical presentations and epidemiology of beta-haemolytic streptococcal bacteraemia: a population-based study. Clin Microbiol Infect. 2009;15:286-288. doi:10.1111/j.1469-0691.2008.02672.x

69. Harris P, Siew P, Proud M, Buettner P, Norton R. Bacteraemia caused by beta-haemolytic streptococci in North Queensland: changing trends over a 14-year period. Clin Microbiol Infect. 2011;17:1216-1222. doi:10.1111/j.1469-0691.2010.03427.x

70. Wong SS, Lin YS, Mathew L, Rajagopal L, Sepkowitz D. Increase in group $\mathrm{G}$ streptococcal infections in a community hospital, New York, USA. Emerg Infect Dis. 2009;15:991-993. doi:10.3201/ eid1506.080666

71. Bruun T, Kittang BR, de Hoog BJ, et al. Necrotizing soft tissue infections caused by Streptococcus pyogenes and Streptococcus dysgalactiae subsp. equisimilis of groups $\mathrm{C}$ and $\mathrm{G}$ in western Norway. Clin Microbiol Infect. 2013;19:E545-550. doi:10.1111/14690691.12276

72. Hashikawa S, Iinuma Y, Furushita M, et al. Characterization of group $\mathrm{C}$ and $\mathrm{G}$ streptococcal strains that cause streptococcal toxic shock syndrome. J Clin Microbiol. 2004;42:186-192.

73. Loubinoux J, Plainvert C, Collobert G, et al. Adult invasive and noninvasive infections due to Streptococcus dysgalactiae subsp. equisimilis in France from 2006 to 2010. J Clin Microbiol. 2013;51:2724-2727. doi:10.1128/JCM.01262-13

74. Lamagni TL, Darenberg J, Luca-Harari B, et al. Epidemiology of severe Streptococcus pyogenes disease in Europe. J Clin Microbiol. 2008;46:2359-2367. doi:10.1128/JCM.00422-08

75. O'Loughlin RE, Roberson A, Cieslak PR, et al. The epidemiology of invasive group A streptococcal infection and potential vaccine implications: United States, 2000-2004. Clin Infect Dis. 2007;45 (7):853-862. doi:10.1086/521264

76. Nelson GE, Pondo T, Toews KA, et al. Epidemiology of invasive group A streptococcal infections in the United States, 2005-2012. Rev Infect Dis. 2016;63:478-486. doi:10.1093/cid/ciw248

77. Lamagni TL, Efstrartiou A, Vuopio-Varkila J, Jasir A, Schalén C; Strep-EURO group. The epidemiology of severe Streptococcus pyogenes associated disease in Europe. Eurosurveillance. 2005;10:e563. doi:10.2807/esm.10.09.00563-en

78. Gattringer R, Sauermann R, Lagler H, et al. Antimicrobial susceptibility and macrolide resistance genes in Streptococcus pyogenescollected in Austria and Hungary. Int $J$ Antimicrob Agents. 2004;24:92-95. doi:10.1016/j.ijantimicag.2004.01.009

79. Krucsó B, Gacs M, Libisch B, et al. Molecular characterisation of invasive Streptococcus pyogenes isolates from Hungary obtained in 2004 and 2005. Eur J Clin Microbiol Infect Dis. 2007;26:807-811. doi:10.1007/s10096-007-0359-4 antibiotic resistance and the mechanisms of resistance development and diffusion in both hospitals and the community. The manuscript management system is completely online and includes a very quick and fair peerreview system, which is all easy to use. Visit http://www.dovepress.com/ testimonials.php to read real quotes from published authors. 